\section{A rare case of acute epiglottitis due to Staphylococcus aureus in an adult}

\author{
Clare Harris, ${ }^{1}$ Lisa Sharkey, ${ }^{1}$ \\ George Koshy, ${ }^{2}$ Nicola Simler, 2 \\ Johannis Andreas Karas ${ }^{3}$
}

'Department of Medicine, Addenbrookes Hospital, Cambridge; ${ }^{2}$ Departments of

Anaesthetics and Medicine,

Hinchingbrooke Hospital

Huntingdon; ${ }^{3} \mathrm{Clinical}$ Microbiology and

Public Health Laboratory, Health

Protection Agency, Addenbrookes

Hospital, Cambridge

\section{Abstract}

Epiglottitis has been mainly associated with childhood infection with Haemophilis influenzae type $B$ but cases of adult epiglottitis are increasing. We report here a case of adult epiglottitis and present evidence that it was caused by Staphylococcus aureus. A 48-year old patient with clinical symptoms of epiglottitis grew Staphylococcus aureus in pure culture from an epiglottal swab. Staphylococcus aureus should be considered as a potential pathogen in adult epiglottitis.

\section{Introduction}

Epiglottitis is a rare infective condition usually associated with childhood infection of the epiglottis with Haemophilius influenzae type $\mathrm{B}$, although evidence is growing that cases of adult epiglottitis are on the increase. ${ }^{1}$ Epiglottitis due to $H$. influenzae has become less common in children following the onset of universal vaccination. ${ }^{2}$ There have been two reports of cases caused by infection due to Staphylococcus aureus. ${ }^{3,4}$ In these cases there has been some debate regarding the strength of the evidence that $S$. aureus is able to cause epiglottitis as there are not documented cases of this infective process with positive blood cultures to verify the underlying pathogen. $S$. aureus is thought to colonise the upper respiratory tract of approximately one fifth of the healthy adult population. ${ }^{5}$ We report here a rare case of epiglottitis and present evidence that it was caused by $S$. aureus.

\section{Case Report}

A 48-year-old female with a history of asthma and excessive alcohol intake presented with shortness of breath to the emergency department after six days of vomiting and a sore throat. She had seen her primary care doctor the day before and had been administered a short course of amoxicillin but was taking no other medications regularly and denied illicit drug use.

On arrival the patient had a tonic-clonic seizure lasting 3 min which was self-terminating and in the post-ictal phase she showed evidence of respiratory distress; tracheal tug, intercostal recession and loud inspiratory noises were observed. Her vital signs were: pulse rate, $150 \mathrm{bpm}$ and regular; respirations, $28 / \mathrm{min}$; oxygen saturation, $94 \%$ on 15 litres of supplemental oxygen.

Whilst her level of consciousness was reduced it was not possible to examine the back of her throat and so intravenous hydrocortisone and chlorpheniramine were administered and the on-call anaesthetist was alerted.

An arterial blood gas showed that she was severely acidotic; $\mathrm{pH} 7.04$, lactate 18 . Her chest radiograph was unremarkable. As she became more alert it was clear that she was unable to speak. The patient was transferred to the intensive care unit on intravenous antibiotics for sepsis secondary to an upper airway infection. She was also commenced on pabrinex and chlordiazperoxide for alcohol withdrawal. The elevated procalcitonin level, white cell count and c-reactive protein supported the diagnosis of severe sepsis (Table 1).

Nine hours later the patient's respiration rate increased to 40/min and her oxygen saturation decreased to $60 \%$ on high flow oxygen therapy; she was intubated as an emergency. During intubation it was noted that she had significant supraglottic swelling with associated creamy coloured secretions. These secretions were sent to the laboratory for culture. The ENT team were initially unable to visualise the oropharynx using flexible laryngoscopy, but confirmed the presence of a congested epiglottis on day four of the admission whilst the patient remained on ITU.

Epiglottis pus culture and nose and throat cultures grew $S$. aureus which was resistant only to penicillin. A gram stain was not obtained at the time of receipt of the sample. The isolate was identified by standard methods and susceptibility testing was done by BSAC methodology. Reference laboratory testing by the Health Protection Agency (HPA), Centre for Infections laboratory was negative for the following Staphylococcal toxin genes: enterotoxin A-J, toxic shock syndrome toxin, exfoliative toxin A, B and D, and Panton Valentine leukocidin.
Correspondence: Johannis Andreas Karas, 3Clinical Microbiology and Public Health Laboratory, Health Protection Agency, Addenbrookes Hospital, Hills Road, Cambridge, CB2 0QQ, UK

Tel. +44.01223.216818. Fax: +44.01223.242774.

E-mail: johannisandreas.karas@addenbrookes.nhs.uk

Key words: epiglottitis, staphylococcus aureus.

Acknowledgements: centre for infections, HPA for toxin testing of the isolate.

Contributions: CH, JAK, manuscript writing; LS, GK, NS, manuscript reviewing.

Conflict of interest: the authors report no conflicts of interest.

Received for publication: 22 September 2011 Revision received: 25 October 2011.

Accepted for publication: 14 December 2011.

This work is licensed under a Creative Commons Attribution NonCommercial 3.0 License (CC BYNC 3.0).

(c) Copyright C. Harris et al., 2012

Licensee PAGEPress, Italy

Infectious Disease Reports 2012; 4:e3

doi:10.4081/idr.2012.e3

The patient improved on intravenous flucloxacillin and was extubated and transferred to a ward for rehabilitation after 14 days. She was also offered advice with regards to alcohol cessation

\section{Discussion}

Epiglottitis is of clinical importance due to its ability to cause sudden and potentially fatal airway obstruction. We report here a case of $S$. aureus epiglottitis in an adult with a strong history of excessive alcohol use. The patient had clinical features of epiglottitis and $S$. aureus was obtained in pure culture from pus taken directly from the epiglottis at the time of intubation. In most cases, throat swabs from adult patients with epiglottitis fail to grow organisms which are pathogenic. ${ }^{6}$

Previously there have not been reported cases of epiglottitis caused by a non-toxin producing strain of $S$. aureus, although there have been cases reported of epiglottitis caused by methicillin-resistant $S$. aureus carrying the Panton-Valentine leukocidin (PVL) gene (Table 2), ${ }^{3,4,-13}$ In our patient the organism was sent to a reference laboratory and was confirmed to be a non-toxin producing strain.

$S$. aureus is an important human pathogen which is known to live as a human commensal, 
colonising the nose and the pharynx of between 10 and 20 percent of the general population. ${ }^{5}$ There is also evidence to suggest that individuals who persistently carry $S$. aureus as a commensal are likely to carry a higher load of the organism, making them more susceptible to infection. ${ }^{14}$ A Scandinavian prospective study into the aetiology of acute epiglottitis in adults found that even when blood cultures, urine samples and serology samples of patients were analysed by polymerase chain reaction (PCR), only 57 percent had an identifiable pathogen. ${ }^{7}$ The Scandinavian study used PCR and serum IgG and IgM antibody ELISA against the capsular polysaccharides of $H$. influenzae type B and Streptococcus pneumoni$a e$. They also used antistreptolysin antibodies to diagnose Group A streptococcal infection. However, they did not fully investigate other potential pathogens (e.g. S. aureus) which may explain the low rate of identifiable pathogens in this study.

In a review of cases over an 18 year period in Rhode Island, 407 cases of acute epiglottitis were identified and the characteristics reviewed. Of the 243 patients who had blood cultures taken, 72 grew $H$. influenzae and none cultured $S$. aureus either in blood or throat swabs. Despite increasing numbers of adult patients developing epiglottitis over time in this study, the number of blood cultures positive for $H$. influenzae did not increase, suggesting an alternative pathogen may be responsible. ${ }^{8}$

In this case, the patient was known to have a high level of alcohol intake, and had also been vomiting for six days prior to admission; these factors could account for an increased infection risk, perhaps through direct trauma to the oropharynx especially if she was already colonised with $S$. aureus.

\section{Conclusion}

We present a case of $S$. aureus epiglotittis proven by pure culture from epiglottic secretions obtained by visualisation of the infected area and directed sampling. $S$. aureus should be considered in cases of adult epiglottitis, as in many cases of epiglottitis the underlying pathogen is not identified and we have established that a non-toxin producing strain can be the causative organism of significant disease. Further studies looking at the aetiology of adult epiglottitis are warranted, and should aim to analyse all samples for a wider range of potential pathogens as often the organism is not identified and the true aetiology of adult epiglottitis remains unknown.
Table 1. Blood results.

\begin{tabular}{lccc} 
& Day 0 & Day 7 & Day 14 \\
White blood cells & 16.2 & 17.5 & 13.4 \\
Haemoglobin & 16.2 & 10.8 & 11.0 \\
\hline Mean corpuscular volume & 113.0 & 112.0 & 108.0 \\
Neutrophils & 12.9 & 13.9 & 9.0 \\
\hline CRP & 114 & 60 & 36 \\
Procalcitonin & 3.03 & 0.48 & - \\
\hline Sodium & 135 & 146 & 147 \\
Potassium & 2.8 & 3.9 & 4.0 \\
\hline Urea & 6.2 & 5.5 & 10.6 \\
Creatinine & 439 & 48 & 69 \\
\hline Bilirubin & 46 & 24 & 18 \\
ALT & 76 & 60 & 85 \\
\hline Alk Phos & 116 & 104 & 106 \\
GGT & 794 & - & - \\
\hline
\end{tabular}

Table 2. Previous studies into the epidemiology of adult epiglottitis.

\begin{tabular}{lccc}
$\begin{array}{l}\text { Study or } \\
\text { case report }\end{array}$ & $\begin{array}{c}\text { Number of } \\
\text { patients }\end{array}$ & $\begin{array}{c}\text { Blood culture } \\
\text { and/or PCR results }\end{array}$ & $\begin{array}{c}\text { Throat/nose } \\
\text { swab results }\end{array}$ \\
$\begin{array}{lcc}\text { Young L, } \\
\text { Price C. } 2007^{3}\end{array}$ & 1 & Meticillin-resistant & Meticillin-resistant \\
Freeman L, & & S. aureus & S. aureus (nasal) \\
Wolford R. $1998^{4}$ & 1 & Meticillin-resistant & Meticillin-resistant \\
S. aureus & S. aureus \\
\hline
\end{tabular}

Trollfors B,

Nylen O et al. $1998^{8}$

Mayo-Smith M,

Spinale J et al. $1995^{9}$

(1)

Wong E, 0

Berkowitz R. 2001 ${ }^{1}$

Mathoera R,

Wever P et al. 2008 ${ }^{11}$

Berg S,

Trollfers B et al. $1996^{12}$

Wick F, Ballmer P. $2002^{13}$

\begin{tabular}{l} 
Wick F, Ballmer P. $2002^{13}$ \\
$\begin{array}{l} \\
\end{array}$ \\
\hline Kucera C, ${ }^{4}$ \\
Silverstein M et al. $1996^{1}$
\end{tabular}

No growth- 23 cases

H. influenzae- 14 cases

Streptococcus pneumoniae- 12 cases

Group A Streptococci- 5 cases cultures sent- 118 cases

No growth- 132 cases

H. influenzae- 19 cases

$\alpha$ haemolytic streptococci- 1 case

$\beta$ haemolytic streptococci- 1 case Propionibacterium species- 1 case Streptococcus pneumoniae- 1 case

$17 \quad$ No cultures- 3 cases

No growth- 11 cases

H. influenzae- 2 cases

Streptococcus mitis- 1 case

No cultures- 13 cases

No growth- 3 cases

No growth- 3 cases

H. influenzae- 1 case

\section{H. influenzae- 114 cases}

Streptococcus pneumoniae- 5 cases

Group A Streptococci- 3 cases

$\begin{array}{cc}\text { No cultures- } 2 \text { cases } & \text { No cultures- } 10 \text { cases } \\ \text { No growth- } 7 \text { cases } & \text { H. influenzae- } 2 \text { cases } \\ \text { H. influenzae- } 1 \text { case } & \\ \text { Streptococcus pneumoniae- } 2 \text { cases } & \\ \text { No cultures- } 12 \text { cases } & \\ \text { No growth- } 5 \text { cases } & \\ \text { H. influenzae- } 3 \text { cases } & \\ \text { Flavobacterium spp- } 1 \text { case } & \end{array}$




\section{References}

1. Berger G, Landau T, Berger S, et al. Rising Incidence of Adult Acute Epiglottitis and Epiglottic Abscess. Am J Otolaryn 2003;24:374-83.

2. Ligon L. Immunization for Haemophilus influenzae type b: Effects on mortality and morbidity in children under five years of age. Semin Pediatr Infect Dis 1998;9:70-6.

3. Young L, Price C. Complicated adult epiglottitis due to meticillin-resistant Staphyloccocus aureus. Am J Otolaryn 2007;28:441-3.

4. Freeman L, Wolford R. Acute Epiglottitis Caused by Methicillin-Resistant Staphylococcus aureus in Adults. Clin
Infect Dis 1998;26:1240-1.

5. Wertheim H, Melles D, Vos M, et al. The role of nasal carriage in Staphylococcus aureus infections. Lancet Infect Dis 2005;5:751-62.

6. Soloman P, Wisbrod M, Irish J, Gullane P. Adult Epiglottitis: The Toronto Hospital experience. J Otolargyn 1998;27:332-6.

7. Trollfors B, Nylen 0, Carenfelt C, et al. Aetiology of acute epiglottitis in adults. Scand J Infect Dis 1998;30:49-51.

8. Mayo-Smith M, Spinale J, Donskey C, et al. Acute epiglottitis, an 18-year experience in Rhode Island. Chest 1995;108:1640-7.

9. Wong E, Berkowitz R. Acute epiglottitis in adults: The Royal Melbourne hospital experience. Anz J Surg 2001;71:740-3.

10. Mathoera R, Wever P, Dorsten F, et al.
Epiglottitis in the adult patient. Neth $\mathrm{J}$ Med 2008;66:373-7.

11. Berg S, Trollfers B, Nylen 0 , et al. Incidence, aetiology, and prognosis of acute epiglottitis in children and adults in Sweden. Scand J Infect Dis 1996;28:261-4.

12. Wick F, Ballmer P, Haller A. Acute epiglottitis in adults. Swiss Med Wkly 2002;132:541-7.

13. Kucera C, Silverstein M, Jacobson R, et al. Epiglottitis in adults and children in Olmsted county, Minnesota, 1976 through 1990. Mayo Clin Proc 1996;71:1155-61.

14. Nouwen JL, Fieren MW, Snijders S, et al. Persistent (not intermittent) nasal carriage of Staphylococcus aureus is the determinant of CPD-related infections. Kidney Int 2005;67:1084-92. 